\title{
Researchers take a stand
}

\section{London}

THE British Association (BA) stepped into the animal rights arena last Friday with its first-ever public declaration of the importance of animal experimentation for the progress of medical research. Prepared over the past few months in response to the increasingly violent attacks of animal rights extremists and included as a late addition to the BA's annual meeting in Swansea, the declaration has the support of a wide array of medical and scientific organizations, including the Medical Research Council (MRC), the Conference of Medical Royal Colleges and the Imperial Cancer Research Fund.

The declaration asserts that animal experiments have made an important contribution to medicine and basic physiology, and that further research "is essential for the conquest of many unsolved medical problems". The scientific community has a duty to explain the aims, methods and benefits of research, it continues, and a responsibility to adhere to animal experimentation legislation and adopt alternatives to animal experiments "as soon as they are proved reliable".

Max Headley, the University of Bristol researcher who narrowly escaped serious injury in an animal-rights car bomb attack earlier this year (see Nature 345, 566; 14 June 1990) hopes the statement will "reassure the public that animal experiments have made a vital contribution [to medicine and veterinary science] and that they must be allowed to do so in future".

Professor Colin Blakemore, a BA vicepresident and a distinguished neurobiologist who has been threatened by animal rights campaigners, says he hopes the document will become "a real charter" for researchers. Blakemore regards the growing influence of the animal-rights campaign on public opinion as part of a wider challenge to the role and authority of science. He believes public statements from leading scientific organizations are important to reverse this trend and has long urged that MRC and others should become openly involved in the animalrights debate (see Nature 343, 3; 1990). Blakemore says that the recent terrorist attacks on animal researchers "have finally brought people off the fence". Ironically, Blakemore says that the declaration, which condemns the violence of animal rights extremists, came on the last day of the BA meeting "because of the fear of reprisals against the local organizers of the conference".

The MRC will in future take a stronger line on the benefits of animal research. A letter from MRC secretary Dai Rees sent to the directors of the council's research units earlier this month says that this year's annual report will contain a state- ment on animal research, and future news releases on medical developments may include references to the use made of animals in experiments. But the MRC has decided against an aggressive propaganda campaign similar to that adopted recently by the British fur industry.

Moderate animal-welfare organizations give the BA declaration a cautious welcome. Les Ward, director of the Scottish group Advocates for Animals says the statement is "well thought out", and hopes that scientists will pursue the alternatives to animal experiments mentioned in the statement "with vigour". But Michael Balls, from the Fund for the Replacement of Animals in Medical Experiments, says that this has not often been the case in the past. He says the signatories must now be "as active in supporting the development of alternatives to animal experiments as they are in defending animal research".

Peter Aldhous

ANIMAL RIGHTS: USA

\section{One step forward...}

\section{Washington}

AgAINST opposition from animal activists and its own staff, the US Department of Agriculture (USDA) last week released for public comment a set of new regulations for the laboratory care of primates, cats and dogs. The rules, which have been at the centre of a five-year battle both inside and outside the administration, are intended to replace the existing regulations of the Animal Welfare Act. USDA's first attempt to provide new regulations failed when objections were raised by the White House in April (see Nature 344, 804; 26 April 1990)

Perhaps the most controversial change made as a result of criticism from the administration is a clause allowing for "innovative caging" that is not in strict accord with minimum cage sizes. The rules set cage the same as those currently prescribed in the guidelines of the National Institutes of Health (NIH), but make an exemption for "enclosures not precisely meeting the [size] requirements, but that do provide non-human primates with a sufficient volume of space and the opportunity to express species-typical behavior". That, in the language of regulators, is known as a "performance-based" rule and is the principal sign of the defeat of USDA, which had insisted that cage parameters should be precisely specified. The winner appears to be the White House, which argued that the rules proposed earlier would have bankrupted the research community. USDA estimated that those rules, with strict minimum cage sizes, would have cost research facilities $\$ 1,750$ million. Costs to facilities are reduced to $\$ 552$ million in the new version.

But USDA officials say that the changes may also make the rules unenforceable. If every laboratory describes its caging as 'innovative', inspectors will no longer be able simply to take out a tape measure to determine infractions, they argue. Instead, rulings on the adequacy of cages will turn on the opinion of other scientists. "You're pitting one expert against another", says Richard Crawford, director of the USDA anımal care staff.
"We're going to have to go to experts wherever they are, and that usually means industry. If industry just circles the wagons, this isn't going to work." Animal welfare activists are no happier. "By including the innovative caging specification they've made every 'shall' a 'should'", says William Cotreau of the Animal Welfare Institute.

But Frankie Trull, president of the National Association for Biomedical Research, says that "innovative" cages are more likely to be the exception than the rule. Even when inspectors are forced to make judgements, the condition of the animals should be the most important consideration, she says.

James Wyngaarden, former NIH director, who until recently handled biomedical issues for the White House Office of Science and Technology Policy, says the new regulations are "a step in the right direction" towards the performancebased rules he had advocated in several critical memoranda to USDA.

The regulations also say that laboratories must "develop, document, and follow a plan" for the psychological well-being of primates. Although the proposed regulations lay out certain objectives, details of the plan are left to each laboratory.

Cotreau, noting that USDA inspectors were able to inspect only a quarter of all dog dealers in 1988, says the additional responsibility of determining what the well-being plan is, whether it is sufficient and whether it is being followed could prove impossible for the overtaxed inspectors. USDA's Crawford says that maintaining a reasonable inspections schedule would probably require more inspectors. But given budget constraints, that could prove difficult, he says.

Unlike the regulations for rabbits, hamsters and guinea-pigs issued last month, the primate and dog regulations have no "grandfather clause". Existing caging is thus included along with new enclosures. USDA has set a deadline of 1 October for comments before preposing a final rule. 